\title{
Analisis Pengaruh Kualitas Pelayanan Sub Bagian Akademik Terhadap Kepuasan Mahasiswa Di Fakultas Kedokteran Universitas Diponegoro Semarang
}

\author{
Dyah Ayu Belawanti Sarbina ${ }^{1}$, Rr. Lulus Prapti N.S.S ${ }^{2}$, Dian Triyani ${ }^{3}$ \\ ${ }^{1}$ S1 Manajemen, FE, Universitas Semarang,Semarang,Indonesia \\ ${ }^{2}$ S1 Manajemen, FE, Universitas Semarang,Semarang,Indonesia \\ ${ }^{3}$ S1 Manajemen, FE, Universitas Semarang,Semarang Indonesia
}

\section{INFO ARTIKEL}

Proses Artikel

Dikirim :

Diterima:

Dipublikasikan:April 2021

\begin{abstract}
ABSTRAK
Riset ini bemaksud guna mengenal bobot layanan sub bagian akademik berkenaan kepuasan mahasiswa. Obyek pada penelitian ini di Fakultas Kedokteran Universitas Diponegoro. Komponen independen pada riset ini adalah bukti nyata (tangibles), kemampuan reaksi (responsiveness), kehandalan (realibility), empati (empathy), dan jaminan (assurance). faktor dependen dalam riset ini ialah kepuasan mahasiswa Fakultas Kedokteran Universitas Diponegoro.

Populasi pada riset ini sebanyak 4522 mahasiswa aktif dengan sampel yang digunakan sejumlah 97 mahasiswa. Teknik yang dipakai dalam pengambilan sampel ialah metode probability sampling berdasarkan teknik proportional stratified random sampling. Riset ini memakai alat Analisis Regresi Linear Berganda.

Kesimpulan Riset memperlihatkan kalau aspek bukti nyata (tangibles), kemampuan reaksi (responsiveness), kehandalan (realibility) dan empati (empathy) secara parsial berdampak positif dan signifikan kepada kepuasan pelanggan sedangkan variabel jaminan (assurance) tidak berakibat kepada kepuasan mahasiswa di Fakultas Kedokteran Universitas Diponegoro.

Kata Kunci :

bukti fisik (tangibles), kemampuan reaksi (responsiveness), kehandalan (reability), empati (emphaty), jaminan (assurance), kepuasan mahasiswa
\end{abstract}

\section{PENDAHULUAN}

Pada kondisi saat ini dengan kondisi zaman yang bertambah maju, hal ini berpengaruh terhadap tingginya keinginan masyarakat buat melanjutkan pendidikan di Perguruan Tinggi. Pendidikan yang tinggi dirasa oleh masyarakat dapat meningkatkan Sumber Daya Manusia (SDM) yang berkompeten dan bermutu. Hal ini sesuai dengan dengan visi dan misi Perguruan Tinggi ialah lembaga pembuat dan penghasil SDM ulung selaku jembatan di dalam melahirkan produk bermutu buat bisa bertarung di pasar global (Marthalina, 2018).

Pada kelanjutannya perguruan tinggi bukan hanya dipandang selaku sentral ilmu pengetahuan, namun di bidang lain perguruan tinggi diminta agar mengeksplorasi dan menaikkan semua segi 
pelayanan prima yang dapat berdampak pada kenaikan citra perguruan tinggi dan kebalikannya servis yang jelek akan meninggalkan citra perguruan tinggi itu sendiri (Siti, 2005 dalam Arifah, 2016). Oleh karena itu, saat ini antar Perguruan Tinggi akan semakin dituntut untuk selalu memberikan servis yang bagus sebab mahasiswa selalu mengejar perguruan tinggi yang melakukan pelayanan terbaik untuknya.

Pola baru Tata laksana pendidikan tinggi mengacu pada lima pilar: "kualitas, otonomi, akuntabilitas, akreditasi, dan evaluasi” (Dirjen Dikti, 1990). Penerapan model itu berguna buat menjadikan sasaran akhir pengembangan kualitas secara berkesinambungan. Tata laksana pengembangan mutu pendidikan tinggi ditafsirkan sebagai layanan profesional publik yang dilakukan dan dipandu setinggi-tingginya buat mempersembahkan layanan yang standar atau melebihi standar. Artinya servis yang dikasihkan perguruan tinggi harus bermutu supaya memperoleh pengakuan masyarakat atau publik. Hal ini bermakna sekurang-kurangnya perguruan tinggi wajib mempunyai tolok ukur pelayanan atau melaksanakan penilaian layanan pada para pelanggan dalam rangka menaikkan mutu pendidikannya (Arifah, 2016).

Dalam suatu organisasi, potensi manusia menggambarkan sebuah elemen terpenting supaya salah satu organisasi bisa berjalan dengan baik. minus adanya elemen termaktub atau kualitasnya yang kurang baik maka akan lebih sulit akan mencapai tujuan organisasi tersebut. Hal ini juga dipengaruhi Tata laksana SDM pada organisasi itu sendiri. Tata laksana sumber daya manusia melukiskan sebuah perencanaan, pengorganisasian, pengkoordinasian, pelaksanaan dan pengawasan pengadaan, pengembangan, pemberian balas jasa, pengintegrasian, pemeliharaan dan pemisahan tenaga kerja dalam rangka mendapatkan maksud organisasi (Mangkunegara, 2013). Sebab itu, kesuksesan sebuah organisasi bisa ditentukan oleh baik buruknya pengelolaan sumber daya manusia pada organisasi tersebut.

Di bidang pendidikan, jenis sumber daya berlandaskan ruang lingkup peran sertanya dalam pengelolaan pendidikan dipisahkan ke dalam SDM Pendidikan sekolah dan SDM pendidikan luar sekolah. Bila ditilik dari bidang tupoksinya, dibagi menjadi tenaga teknis, tenaga administratif dan tenaga penunjang. Berikutnya menurut PP 38/1992 mengenai Tenaga Kependidikan pengelompokannya adalah tenaga pendidik, (pembimbing, pengajar, pelatih), pengelolaan, pengawas, laporan, teknisi sumber belajar, peneliti dan penguji (Amirudin, 2017).

Fakultas Kedokteran Universitas Diponegoro merupakan institusi yang salah satu tujuannya adalah untuk melahirkan peserta didik jadi dokter dan tenaga kesehatan yang mempunyai keahlian akademik dan professional sehingga bisa berkompetisi di lingkup nasional maupun internasional.. Hal ini tentu saja perlu disokong oleh sumber daya manusia yang ada baik dari tenaga pendidik maupun tenaga kependidikan. Peran tenaga pendidik (dosen) sungguh diperlukan dalam membantu mahasiswa yakni berupa sistem pembelajaran guna bisa membuat mahasiswa yang bermutu, dan perlu didukung dari segi pelayanan oleh tenaga kependidikan dalam membantu mahasiswa untuk mendapatkan pendidikan yang layak sehingga pelayanan yang diberikan haruslah semaksimal mungkin. Program studi di Fakultas Kedokteran Universitas ada sebanyak 30 mencakup lima prodi Sarjana, dua prodi Profesi, tiga prodi Magister, satu prodi Doktor dan 19 program studi Spesialis. Masing - masing program studi memiliki layanan akademik dimana layanan akademik tersebut berada di bawah naungan Sub Bagian Akademik Fakultas Kedokteran Universitas Diponegoro. Bagian Akademik memiliki kewajiban menjalankan administrasi akademik, penelitian dan pengabdian kepada masyarakat. 
Pada hasil penelitian sebelumnya oleh Juni, 2014 yang berjudul "Pengaruh Kualitas Pelayanan terhadap Kepuasan Mahasiswa Fakultas Ekonomi Universitas Surakarta" diperoleh hasil bahwa berwujud (tangibles), kehandalan (reliability), kemampuan reaksi (responsiveness), jaminan (assurance) dan empati (empathy) berdampak secara signifikan kepada kepuasan mahasiswa, dimana variable berwujud (tangibles) memiliki dampak amat besar kepada kepuasan mahasiswa. Hal ini berbeda dengan hasil riset Vinny dkk, 2017 dalam judul "Pengaruh Kualitas Pelayanan Akademik terhadap Kepuasan Mahasiswa" di Mahasiswa Admnistrasi Bisnis Universitas Telkom diperoleh efek bahwa variable kemampuan reaksi (responsiveness) dan variable tangible (bukti fisik) memiliki pengaruh secara konkret kepada kepuasan mahasiswa adapun variable kehandalan (reliability), jaminan (assurance) dan empati (emphaty) tidak mempunyai pengaruh kepada kepuasan mahasiswa.

Berdasarkan penelitian sebelumnya, maka perlu dilakukan penelitian agar mengetahui bagaimana pengaruh kelima variable tersebut terhadap kepuasan mahasiswa di Fakultas Kedokteran Universitas Diponegoro serta dilakukan evaluasi kualitas pelayanan akademik sehingga diharapkan pelayanan akademik dapat ditingkatkan agar pegawai dapat melaksanakan pelayanan yang professional seperti yang diinginkan oleh mahasiswa. Dengan demikian, penulis ingin membuat riset dengan berjudul "Analisis Pengaruh Kualitas Pelayanan Sub Bagian Akademik terhadap Kepuasan Mahasiswa di Fakultas Kedokteran Universitas Diponegoro Semarang” dengan harapan bisa membagikan manfaat pada organisasi untuk memberikan motivasi kepada pegawai agar terwujudnya maksud organisasi.

Menilik pada latar belakang sebelumnya maka bisa dirumuskan masalah yaitu "Bagaimana cara meningkatkan kualitas pelayanan kinerja pegawai administrasi kademik di Fakultas Kedokteran UNDIP Semarang" dengan pertanyaan penelitian berikut :

a. Apakah berpengaruh bukti nyata (Tangibles) kepada kepuasan mahasiswa di Fakultas Kedokteran UNDIP?

b. Apakah berpengaruh kemampuan reaksi (Responsiveness) kepada kepuasan mahasiswa di Fakultas Kedokteran UNDIP?

c. Bagaimana pengaruh kehandalan (Reliability) kepada kepuasan mahasiswa di Fakultas Kedokteran UNDIP?

d. Bagaimana pengaruh empati (Empathy) kepada kepuasan mahasiswa di Fakultas Kedokteran UNDIP?

e. Bagaimana pengaruh jaminan (Assurance) kepada kepuasan mahasiswa di Fakultas Kedokteran UNDIP?

Menilik latar belakang dan rumusan masalah di atas maka maksud riset ini ialah :

a. Guna menelaah pengaruh bukti nyata (Tangibles) kepada kepuasan mahasiswa di Fakultas Kedokteran UNDIP.

b. Untuk menelaah efek kemampuan reaksi (Responsiveness) kepada kepuasan mahasiswa di Fakultas Kedokteran UNDIP.

c. Guna menelaah kehandalan (Reliability) kepada kepuasan mahasiswa di Fakultas Kedokteran UNDIP.

d. Guna menganalisis empati (Empathy) kepada kepuasan mahasiswa di Fakultas Kedokteran UNDIP.

e. Guna menganalisis pengaruh jaminan (Assurance) Kepada kepuasan mahasiswa di Fakultas Kedokteran Universitas Diponegoro. 


\section{Variabel penelitian}

\section{METODE PENELITIAN}

adalah nilai sebuah objek, orang atau aktivitas yang memiliki variasi khusus seperti ditentukan oleh peneliti guna diteliti dan diambil kesimpulannya (Sugiyono, 2011). Komponen yang dipakai dalam riset ini diantaranya:

\section{a. Komponen Bebas (Independent Variabel)}

adalah varaiabel yang menyebabkan perusahaan atau lahirnya variable terikat. Penelitian ini yang tergabung dalam ahasae bebas adalah :
1. Bukti Fisik (Tangibles)
2. Kemampuan reaksi (Responsiveness)
3. Kepercayaan atau kehandalan (Reliability)
4. Empati (Emphaty)
5. Keyakinan (Assurance)

b. Variabel Terikat (Dependent Variabel)

adalah variabelnya dilihat dan ditimbang guna memutuskan pengaruh yang diakibatkan oleh variabel bebas. Penelitian ini variabel dependennya ialah Kepuasan Maahasiswa (Y).

\section{Objek Penelitian dan Unit Sampel}

Objek riset ini ialah Fakultas Kedokteran UNDIP yang berada di Jalan Prof. H. Soedarto,SH , Tembalang Semarang yang merupakan salah satu fakultas di UNDIP terdiri dari 29 program studi.

Unit sampel yang dipakai kedalam riset ini adalah :

a. Data primer dalam hal ini Mahasiswa di Fakultas Kedokteran UNDIP

b. Data sekunder yang dipakai ialah laporan evaluasi kinerja tenaga kependidikan di Fakultas Kedokteran UNDIP.

\section{Populasi}

adalah daerah penyamarataan yang mencakup: obyek/subyek yang memiliki mutu dan kekhususan terpilih sesuai ketetapan peneliti guna diteliti dan selanjutnya diambil kesimpulannya (Sugiyono,2011). Populasi dalam riset ini adalah semua mahasiswa di Fakultas Kedokteran UNDIP sebanyak 4522 orang yang tercatat sebagai mahasiswa aktif.

\section{Sampel}

ialah irisan atau besaran dan kekhususan yang dipunyai oleh komunitas itu. Pabila komunitas besar, dan peneliti tidak bisa mengamati seluruh populasi, misal sebab keterbatasan anggaran, tenaga dan waktu, maka peneliti memakai sampel dari populasi itu. Apa yang diteliti dari sampel itu, kesimpulannya tetap berlaku buat populasi. Karena itu sampel yang dipakai dari populasi benar-benar representative (Sugiyono,2011). 
Teknik sampling adalah teknik pengambilan sampel untuk menetukan sampel yang akan dipakai dalam riset (Sugiyono, 2011). Dalam riset ini teknik pengambilan sampelnya adalah metode probability sampling dengan teknik proportional stratified random sampling yaitu pengambilan sampel yang dipakai agar mahasiswa masing - masing jenjang studi dapat diwakili secara proporsional dan rasional. Sampel yang dihasilkan sebesar 97 mahasiswa.

\section{Analisis Linier Berganda}

Analisis regresi ialah ilmu perihal keterkaitan faktor dependen (terikat) dengan satu atau lebih variabel independen (bebas), bertujuan guna menerka juga memperkirakan rata-rata populasi atau nilai-nilai variabel dependen berlandaskan nilai variabel independen yang diketahui (Ghozali, 2005). Guna regresi yang faktor independennya terdiri atas dua atau lebih, regresinya disebut juga regresi berganda. Oleh sebab variabel independen yang dipakai lebih dari satu, lalu regresi dalam riset ini disebut regresi berganda. Rumus persamaan regresi berganda yang dipakai dalam riset ini ialah

$$
Y=a+\beta_{1} X_{1}+\beta_{2} X_{2}+\beta_{3} X_{3}+\beta_{4} X_{4}+\beta_{5} X_{5}
$$

Keterangan:

$$
\begin{array}{ll}
\mathrm{Y} & =\text { Kepuasan Mahasiswa } \\
\mathrm{X}_{1} & =\text { Bukti Fisik (Tangibles) } \\
\mathrm{X}_{2} & =\text { Daya Tanggao (Responsiveness) } \\
\mathrm{X}_{3} & =\text { Kepercayaan atau Keandalan (Reliability) } \\
\mathrm{X}_{4} & =\text { Empati (Emphaty) } \\
\mathrm{X}_{5} & =\text { Keyakinan (Assurance) } \\
\mathrm{a} & =\text { Konstanta } \\
\mathrm{B} & =\text { koefisien regresi standarized }
\end{array}
$$

\section{HASIL DAN PEMBAHASAN}

Bersumber perolehan analisis regresi linear berganda dihasilkan persamaan seperti berikut :

Kepuasan Mahasiswa $=0,358 \mathrm{X}_{1}+0,208 \mathrm{X}_{2}+0,191 \mathrm{X}_{3}+0,262 \mathrm{X}_{4}+0,045 \mathrm{X}_{5}$

a. Nilai koefisien bukti fisik (X1) diperoleh hasil sebesar 0,358 bernilai positif. Hal ini bermakna apabila bukti fisik bertambah bagus mengakibatkan kepuasan mahasiswa semakin bertambah atau kebalikannya, bila bukti fisik semakin jelek maka kepuasan mahasiswa akan turun.

b. Nilai koefisien kemampuan reaksi (X2) diperoleh hasil sebesar 0,208 bernilai baik. Keadaan ini bermakna apabila responsif maka kebahagiaan mahasiswa juga akan bertambah meningkat atau sebaliknya, jika kurang responsif maka kepuasan mahasiswa juga mengalami penurunan.

c. Nilai koefisien kehandalan (X3) diperoleh hasil sebesar 0,191 bernilai positif. Hal ini bermakna apabila kehandalan meningkat lalu kebahagiaan mahasiswa juga makin bertambah 
atau kebalikannya, bilamana kehandalan menurun maka kepuasan mahasiswa juga makin mengalami penurunan.

d. Nilai koefisien empati (X4) dipeoleh hasil sebesar 0,262 berharga positif. Situasi ini bermakna pabila empati bertambah maka kepuasan mahasiswa juga akan bertambah atau sebaliknya, jika empati menurun maka kepuasan mahaiswa juga akan mengalami penurunan.

e. Nilai koefisien jaminan (X5) diperoleh hasil sebesar 0,045 bernilai positif. situasi ini bermakna pabila jaminan bertambah maka kepuasan mahasiswa juga akan mengalami penambahan, atau kebalikannya jika jaminan menurun makan kepuasan mahasiswa juga akan menurun.

f. Berdasarkan hasil tersebut bisa didapati kalau variabel bukti fisik (X1) memiliki nilai pengaruh paling tinggi kepada kepuasan mahasiswa sedangkan variabel jaminan (X5) memiliki nilai pengaruh paling rendah kepada kepuasan mahasiswa.

\section{Pengaruh Bukti Fisik terhadap Kepuasan Mahasiswa}

Bersumber pada hasil penelitian yang telah dilakukan diperoleh bahwa faktor data fisik berakibat positif secara signifikan kepada kepuasan mahasiswa. Keadaan ini bermakna data fisik yang bertambah baik bakal menambah kepuasan mahasiswa. Menurut Pasuraman (2001), data fisik dalam mutu layanan ialah wujud manifestasi nyata secara fisik bisa tampak atau dipakai sama pegawai seperti dengan penggunaannya yang bisa dirasakan membantu jasa yang diperoleh oleh orang yang mengharapkan pelayanan, hingga puas atas pelayanan yang dirasakan, yang sekaligus memperlihatkan hasil kerja atas pelayanan yang diberikan.

Mulai hasil distribusi frekuensi tanggapan mahasiswa bisa diperoleh kalau sebagian besar mahasiswa puas terhadap kebersihan tempat pelayanan, fasilitas fisik yang ada, ketersediaan perlengkapan, serta kerapian penampilan petugas. Hal ini diperlihatkan sama diperolehnya nilai rata-rata sebesar 3,93.

Maka demikian kepuasan mahasiswa bisa bertambah bila mahasiswa merasa puas sama tempat pelayanan yang bersih dan nyaman, fasilitas fisik yang memadai, penyediaan perlengkapan yang seperti keinginan dan kebutuhan mahasiswa, dan kerapian keryawan. Oleh karena itu, pihak Fakultas Kedokteran Universitas Diponegoro perlu menambah bukti fisik yang ada, sebab bukti nyata dalam bobot layanan ialah bentuk manifestasi riil secara nyata bisa diamati atau dipergunakan sama karyawan sehingga dapat membantu pelayanan terhadap mahasiswa agar mahasiswa merasa puas terhadap pelayanan yang disediakan.

Hasil riset ini sama seperti hasil yang telah dilaksanakan oleh Abdullah Taman (2013) yang diperoleh hasil kalau nyata(tangible) berdampak baik dan sangat berarti kepada kebahagiaan konsumen. Riset Ishaq Ahmed (2010) juga didapatkan hasil bukti fisik (tangible) berdampak baik dan sangat berarti kepada kebahagiaan konsumen.

\section{Pengaruh Kemampuan reaksi terhadap Kepuasan Mahasiswa}

Berpatokan kepada penelitian yang sudah dilaksanakan diperoleh kalau komponen bukti fisik berdampak positif secara signifikan kepada kepuasan mahasiswa. Hal ini berarti respon yang bertambah baik maka kepuasan mahasiswa jadi bertambah. Menurut Pasuraman (2001), kemampuan reaksi (responsiveness) merupakan potensi perusahaan yang dilaksanakan tanpa perantara sama karyawan buat melayani secara cepat dan peka. Kepekaan bisa menghasilkan pandangan yang baik kepada mutu pelayanan yang dikasihkan. 
Dengan demikian, meningkatnya kemampuan petugas pelayanan akademik dalam menyelesaikan keluhan mahasiswa lebih cepat maka kepuasan mahasiswa akan semakin meningkat sehingga keluhan yang dialami oleh mahasiswa segera terselesaikan.

Pada hasil distribusi frekuensi tanggapan mahasiswa bisa didapati kalau sebagian besar mahasiswa puas terhadap sikap tanggap petugas terhadap keluhan mahasiswa, kesediaan petugas dalam membantu mahasiswa dan petugas cepat dalam menyelesaikan masalah yang dialami mahasiswa. Hal ini diperlihatkan dengan diperolehnya hasil rata-rata sebesar 3,84.

Keluaran riset ini sama seperti penelitian yang dilaksanakan Vinny dan Nurnida (2017) yang diperoleh keluaran kalau kemampuan reaksi berdampak secara relevan kepada kepuasan mahasiswa. Begitu pula, hasil yang diperoleh pada penelitian Juni (2014) yakni variabel responsiveness (kemampuan reaksi) berdampak kepada kepuasan mahasiswa.

\section{Pengaruh Kehandalan terhadap Kepuasan Mahasiswa}

Pada akhir riset tersebut diperoleh hasil variabel kehandalan berpengaruh positif secara relevan kepada kepuasan mahasiswa. keadaan ini berarti kehandalan yang bertambah bagus lalu kepuasan mahasiswa bakal meningkat. Menurut Pasuraman (2001), kehandalan (reliability) adalah keahlian perusahaan buat mejalankan jasa seperti apa yang sudah disepakati dengan handal dan akurat.

Berdasarkan hasil pembagian frekuensi isian mahasiswa bisa didapati kalau sebagian besar mahasiswa puas terhadap sikap petugas yang cepat dalam melayani mahasiswa, prosedur pelayanan yang tidak terbelit - belit, serta pelaksanaan teknis yang tepat waktu contohnya pada saat pelaksanaan ujian nasional OSCE, ujian skripsi, ujian tesis, ujian disertasi, BBDM, perkuliahan dan lain sebagainya. keadaan ini bisa diperlihatkan dengan diperolehnya nilai ratarata responden sebesar 3,68. Namun, masih perlu diperbaiki terutama mengenai prosedur pelayanan akademik yang lebih jelas dan sistematis agar lebih memudahkan mahasiswa untuk mengurus perihal yang berkaitan dengan akademik.

Hasil riset ini seperti dengan riset yang dilaksanakan Fera (2019) yang diperoleh hasil variabel reliability (kehandalan) berakibat positif dan signifikan kepada kepuasan pelanggan Selain itu, mendukung riset Rivan (2019) yang diperoleh hasil kalau reliability berakibat positif kepada kepuasan pelanggan.

\section{Pengaruh Empati terhadap Kepuasan Mahasiswa}

Berpatokan hasil riset yang sudah dilaksanakan diperoleh kalau faktor empati berpengaruh positif secara signifikan kepada kepuasan mahasiswa. peristiwa ini bermakna empati yang bertambah bagus maka kepuasan mahasiswa semakin bertambah. Menurut Parasuraman (2001), empati (empathy) adalah keahlian perusahaan yang dilaksanakan langsung oleh karyawan buat memberikan kepedulian pada pelanggan secara personal, termasuk juga kepekaan atau kebutuhan pelanggan.

Mulai hasil penyaluran frekuensi tanggapan mahasiswa bisa dilihat kalau sebagian besar mahasiswa puas terhadap pelayanan akademik karena petugas dapat melihat dan mengerti keinginan mahasiswa serta bisa berkomunikasi dengan baik. Hal ini bisa diperlihatkan dengan nilai rata-rata responden sebesar 3,90. Namun, masih perlu ditingkatkan terutama bentuk perhatian secara langsung yang diberikan oleh petugas pelayanan kepada mahasiswa agar mahasiswa merasa puas kepada pelayanan yang diterima sesuai dengan harapannya. 
Hasilnya riset ini sama seperti penelitian yang sudah dilaksanakan oleh Roby (2014) maka variabel emphaty berdampak positif dan signifikan kepada kepuasan pelanggan. Hal ini juga mendukung penelitian Sasongko (2013) yang diperoleh hasil variabel emphaty berdampak baik dan signifikan kepada kepuasan pelanggan.

\section{Pengaruh Jaminan terhadap Kepuasan Mahasiswa}

Berlandaskan hasil riset yang sudah dilaksanakan lalu didapatkan hasil kalau jaminan tidak berdampak dan tidak signifikan kepada kepuasan mahasiswa yang berarti bentuk jaminan apapun yang telah diberikan oleh petugas pelayanan akademik Fakultas Kedokteran Universitas Diponegoro tidak akan berpengaruh apapun terhadap kepuasan mahasiswa. Hal ini dapat dikarenakan pada variabel jaminan (assurance) merupakan sesuatu variabel yang tidak bisa dirasakan dampaknya secara spontan oleh mahasiswa dan selain itu dapat dipengaruhi oleh intensitas keperluan mahasiswa di pelayanan akademik. Mahasiswa yang lebih sering ke sub bagian akademik akan lebih mengetahui bentuk pelayanan yang diberikan oleh petugas dibandingkan mahasiswa yang jarang ke sub bagian akademik. Mahasiswa yang jarang ke sub bagian akademik akan sangat jarang sekali menjumpai kendala dalam pelayanan sehingga dapat diasumsikan bahwa mahasiswa puas dengan jaminan yang diberikan.

Hasil riset ini tidak sama seperti penelitian Flady (2020) yang diperoleh hasil kalau variabel assurance berdampak positif dan signifikan kepada kepuasan mahasiswa. Namun, perihal ini sama seperti riset Vinny (2017) yang menjelaskan kalau variabel assurance secara parsial tidak berdampak dan tidak signfikan kepada kepuasan mahasiswa. Selain itu, juga mendukung penelitian Soenaryo (2015) yang diperoleh hasil kalau variabel assurance tidak berdampak dan signifikan kepada kepuasan pelanggan.

\section{KESIMPULAN DAN SARAN}

Berlandaskan hasil penelitian bisa disimpulkan sebagai berikut :

1. Variabel bukti fisik berdampak positif secara signifikan kepada kepuasan mahasiswa. Bukti fisik yang bertambah bagus akan menambah kepuasan mahasiswa.

2. Variabel daya respon berdampak positif secara signifikan kepada kepuasan mahasiswa. Kemampuan reaksi yang bertambah bagus lalu kepuasan mahasiswa akan meningkat

3. Variabel kehandalan berdampak positif secara signifikan kepada kepuasan mahasiswa. Kehandalan yang semakin baik maka kepuasan mahasiswa semakin bertambah.

4. Variabel empati berdampak positif secara signifikan kepada kepuasan mahasiswa. Empati yang semakin baik maka kepuasan mahasiswa semakin bertambah.

5. Variabel jaminan tidak berdampak dan tidak signifikan kepada kepuasan. Bentuk jaminan apapun yang telah diberikan tidak akan berpengaruh apapun terhadap kebahagiaan mahasiswa. 


\section{DAFTAR PUSTAKA}

Alfiani, Arifah. 2016. Kepuasan Mahasiswa Terhadap Pelayanan Administrasi Akademik Di Subbag Pendidikan Fakultas Ilmu Pendidikan Universitas Negeri Yogyakarta. Skripsi. Universitas Negeri Yogyakarta.

Amirudin (2017), Kinerja Pegawai Tata usaha dengan Mutu Layanan Administrasi di Madrasah, Jurnal AlIdarah

Arimawati, Renata dan Djastuti, Indi. 2013. Pengaruh Kualitas Pelayanan Kinerja Pegawai Administrasi Akademik Terhadap Kepuasan Mahasiswa Fakultas Ekonomika Dan Bisnis Universitas Diponegoro. Diponegoro Journal Of Management : Volume 2, Nomor 2, Tahun 2013, Halaman 1- 9. Semarang.

Akbar, Robby Nur. 2016. Pengaruh Kualitas Pelayanan Terhadap Kepuasan Pelanggan ( Studi pada Nasabah Prioritas PT. AIA Financial cabang Malang, Jawa Timur ) . Jurnal Administrasi Bisnis (JAB)|Vol. 30 No. 1 Januari 2016. Universitas Brawaijaya. Malang.

Barry, Rivan Khairu. 2019. Pengaruh Dimensi Kualitas Pelayanan Terhadap Kepuasan Pelanggan Pada Pt. Mandalatama Armada Motor. Skripsi. Universitas Semarang.

Darmadji, T., \& Fakhruddin, H. M. (2001). Pasar Modal Di Indonesia: Pendekatan Tanya Jawab. Salemba Empat.

Endang, Fatmawati. (2003). Analisis Kualitas Pelayanan Pada Bagian Administrasi Fakultas Ekonomi UNDIP. Tesis. Universitas Diponegoro.

Fauziah, Luluk. 2019. Dimensi Kualitas Layanan Terhadap Kepuasan Pelanggan Bengkel Ahass 00002 Siliwangi Semarang. Skripsi. Universitas Semarang

Fera Maulina (2019), Analisis Pengaruh Kualitas Pelayanan terhadap Kepuasan Nasabah pada Bank Syariah Mandiri Singkawang

Fuad Mas’ud. 2004.Survei Diagnosis Organisasional.Badan Penerbit UNDIP

Ghozali, Imam (2005), Aplikasi Analisis Multivariate dengan SPSS, Semarang, Badan Penerbit UNDIP

Irawan, H. (2002). 10 Prinsip Kepuasan Pelanggan. Penerbit PT. Elex Media Komputindo Gramedia, Jakarta.

Juhana, Dudung dan Mulyawan, Ali. 2015. Pengaruh Kualitas Layanan Jasa Pendidikan terhadap Kepuasan Mahasiswa di STMIK Mardira Indonesia Bandung. Jurnal Ekonomi, Bisnis \& Entrepreneurship Vol.9, No.1, April 2015 1-15 ISSN 2443-0633. STTMIK Mardira Indonesia. Bandung.

Kotler, Philip dan A.B Susanto. 2000. Tata laksana Pemasaran Jasa Di Indonesia, Analisis Perencanaan, Implementasi dan Pengendalian (Edisi Pertama). Jakarta: Salemba Empat.

Kotler, P., \& Keller, K. L. (2002). Tata laksana Pemasaran: Analisis, Perencanaan dan Pengendalian edisi Bahasa Indonesia. Jakarta: PT. Erlangga.

Kotler, Philip, dan Garry. Armstrong. 2012. Prinsip Prinsip Pemasaran, Edisi 13, Jilid 1, Jakarta, Erlangga.

Kurniasari, Fera. 2019. Pengaruh Dimensi Kualitas Pelayanan Pada Kepuasan Pelanggan (Studi Pada Pelanggan Hotel Bliss Soetta Semarang). Skripsi. Universitas Semarang.

Lovelock CH. (2002). Service Marketing. Second Edition, Englewood Cliffs, New Jersey: Prentice Hal Inc.

Mangkunegara, AA Anwar Prabu (2013), Tata laksana Sumber Daya Manusia Perusahaan, Remaja Rosdakarya, Bandung

Marthalina, (2018), Analisis Kualitas Pelayanan Akademik dan Kepuasan Mahasiswa di IPDN Kampus Jakarta, Jurnal Tata laksana Sumber Daya manusia, 5 
Nasution, S. (2004). Metode Riset Penelitian Ilmiah. Cetakan Ketujuh. Jakarta: Penerbit Bumi Aksara.

Parasuraman ,A. L.L. Berry, and V.A. Zeithaml (1988), :SERVQUAL : A Multiple- Item Scale for Measurung Concumer Perception of Service Quality. Cambridge,Mass: Marketing.

Pratama, Flady Dian dan Asmoro, Eddi Indro. 2020. Pengaruh Kualitas Pelayanan Akademik Terhadap Tingkat Kepuasan Mahasiswa (Studi Kasus Di Fakultas Teknik Prodi Teknik Industri Unisbank Semarang). Jurnal Dinamika Teknik Vol. XIII No. 1 Januari 2020 ISSN : 1412-3339. Universitas Stikubank. Semarang.

Rahareng, Vinny Jennifer dan Relawan, Nurnida. 2017. Pengaruh Kualitas Pelayanan Akademik Terhadap Kepuasan Mahasiswa (Studi Pada Mahasiswa Administrasi Bisnis Universitas Telkom). Jurnal AdBispreneur Vol.2, No.2 Agustus 2017 Hal. 125-133. Universitas Telkom.

Sugiyono. 2012. Metode Penelitian Kuantitatif, Kualitatif, dan R\&D. Bandung: Alfabeta

Sasongko, Felita. 2013. Pengaruh Kualitas Layanan Terhadap Kepuasan Pelanggan Restoran Ayam Penyet Ria. Jurnal Tata laksana Pemasaran Petra Vol. 1, No. 2, (2013) 1-7

Sukanti. (2009). Analisis Kepuasan Mahasiswa Program Studi Pendidikan Akuntansi FISE UNY. Jurnal Pendidikan Akuntansi Indonesia (Vol. Viii. Nomor 1). Hal 23 - 3.

Tjiptono, F., \& Chandra, G. (2005). Service, Quality dan Satisfaction. Yogyakarta: Andi.

Taman, Sukirno dkk. 2013. Analisis Kualitas Pelayanan Terhadap Kepuasan Mahasiswa Pada Fakultas Ekonomi Universitas Negeri Yogyakarta. Jurnal Nominal Volume II Nomor 1.

Tjiptono, Fandy. 2008. Strategy Pemasaran, Edisi III. Yogyakarta: CV. Andi Offset.

Trisnowati, Juni. 2014. Pengaruh Kualitas Pelayanan Terhadap Kepuasan Mahasiswa Fakultas Ekonomi Universitas Surakarta. Jurnal Ekonomi dan Kewirausahaan Vol. 14, No. 2, Oktober 2014: 222 229. Universitas Surakarta.

Zeithaml, Valerie A., Leonard Berry, and A. Parasuraman. 1996. 'The Behavioral Consequence Of Service Quality'. Journal of Marketing, vol. 60.

Zulian, Yamit. 2010. Tata laksana Kualitas Produk \& Jasa. Cet. 5. Yogyakarta: Ekonisia. 